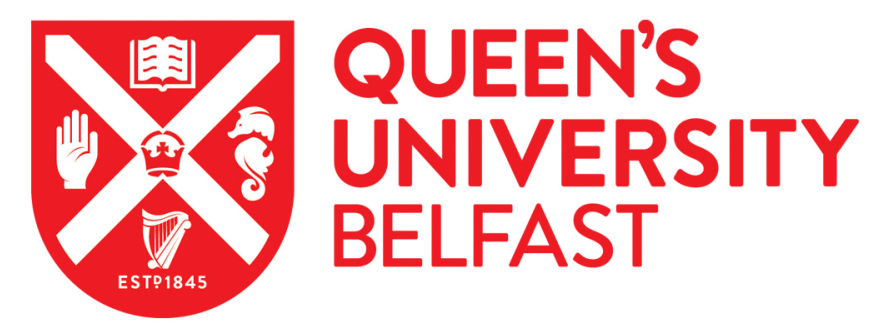

\title{
Autoclave Cure Simulation of Composite Structures Applying Implicit and Explicit FE
}

\author{
Abdelal, G. F., Robotham, A., \& Cantwell, W. (2013). Autoclave Cure Simulation of Composite Structures \\ Applying Implicit and Explicit FE. International Journal of Mechanics and Materials in Design, 9(1), 55-63. \\ https://doi.org/10.1007/s10999-012-9205-7
}

\section{Published in:}

International Journal of Mechanics and Materials in Design

\section{Document Version:}

Peer reviewed version

\section{Queen's University Belfast - Research Portal:}

Link to publication record in Queen's University Belfast Research Portal

\section{Publisher rights}

(C) Springer Science+Business Media Dordrecht 2012

The final publication is available at Springer via http://link.springer.com/article/10.1007\%2Fs10999-012-9205-7

\section{General rights}

Copyright for the publications made accessible via the Queen's University Belfast Research Portal is retained by the author(s) and / or other copyright owners and it is a condition of accessing these publications that users recognise and abide by the legal requirements associated with these rights.

Take down policy

The Research Portal is Queen's institutional repository that provides access to Queen's research output. Every effort has been made to ensure that content in the Research Portal does not infringe any person's rights, or applicable UK laws. If you discover content in the Research Portal that you believe breaches copyright or violates any law, please contact openaccess@qub.ac.uk. 


\title{
Virtual Manufacturing of Composite Structures Applying Implicit and Explicit FE Techniques
}

\author{
Gasser F. Abdelal ${ }^{1 *}$, Antony Robotham ${ }^{2}$, Wesley Cantwell ${ }^{3}$ \\ ${ }^{1}$ The Virtual Engineering Centre, University of Liverpool, Warrington, UK, \\ WA44AD \\ (Email: G.Abdelal@liverpool.ac.uk) \\ ${ }^{2}$ The Virtual Engineering Centre, University of Liverpool, Warrington, UK, \\ WA44AD \\ (Email: Ajr@liverpool.ac.uk) \\ ${ }^{3}$ Centre for Materials and Structures, University of Liverpool, Liverpool, UK, \\ L69 $3 G H$ \\ (Email: Cantwell@liverpool.ac.uk ) \\ *Corresponding Author
}

\section{Abstract}

Simulation of the autoclave manufacturing technique of composites can yield a preliminary estimation of induced residual thermal stresses and deformations that affect component fatigue life, and required tolerances for assembly. In this paper, an approach is proposed to simulate the autoclave manufacturing technique for unidirectional composites. The proposed approach consists of three modules. The first module is a Thermo-chemical model to estimate the temperature and the degree of cure distributions in the composite part during the cure cycle. The second and third modules are a sequential stress analysis using FE-Implicit and FE-Explicit respectively. Usermaterial subroutine is used to model the Viscoelastic properties of the material based on theory of micromechanics.

\section{Keywords}

Autoclave, chemical reaction, composites, cure, exthothermic, explicit, finite element, implicit, micromechanics, thermal stress. 


\section{Introduction}

The main objective of our approach is the early estimation of composite part deformations during autoclave manufacturing. These early estimated deformations can be used to modify autoclave-tool design to achieve better part design within specified tolerances (customer requirements). Numerical autoclave simulation will reduce the cost of the iterative manufacturing process to find the optimized autoclave-tool design.

Autoclave simulation consists of three steps. The first step is a Thermo-Chemical model to simulate the curing cycle and determine the temperature and degree of cure distributions as a function of the cure-cycle time. The second and third components are stress-thermal models based on implicit and explicit techniques, to calculate residual stresses (that can affect part fatigue life) and deformations (that can affect assembly process)[1].

The chemical reaction which occurs during the curing of thermoset composites plays an important role in the process modelling of thermoset composites. The exothermic heat released during the curing process can possibly cause excessive temperatures in the interior of composites. Cure kinetics that provides information on the curing rate and the amount of exothermic heat release during the chemical reaction are important in the process simulation of composite materials with thermoset polymers. A number of different models have been proposed to describe the cure kinetics of various resin systems [2-5]. To characterize the exothermic cross-linking of a thermosetting polymer matrix, a thermal cure monitor technique such as isothermal Differential Scanning Calorimetry (DSC) is commonly used. Capehart, Kia and Abujoudeh [6] discussed the procedure required to fit a selected cure kinetic model to the experimentally-determined cure rates.

A number of different factors lead to the development of residual stresses and deformations, during autoclave process. These factors can be summarized in the following; thermal strains, resin cure shrinkage, and tooling mechanical constraints. Thermal strains are due to the mismatch of thermal properties of the laminate layers, gradient of temperature and resin degree of cure, and the mismatch of thermal expansion coefficients between the part and the tool. Cure shrinkage is reduction in volume due to an increase in resin density during polymerization. Shrinkage strains are higher in the transverse to the fibre direction than in the fibre direction in which they will be largely constrained. The role of cure shrinkage in generating residual stresses was studied by many researchers [7-8]. Process tooling affects part stress development by disturbing the component internal temperature, and via mechanical loads and constraints applied at tool/part interfaces. Disturbing the part internal temperature occurs as a result of the difference in component tool-side and vacuum bag-side temperatures. This factor is significant only for thick composite part. Boundary loads to the part, both in shear and 
normal to the tool/part interface plays a major role in induced residual stresses. The resin mechanical behaviour during curing cycle can be divided to three steps; First stage is a purely viscous behaviour with no internal stresses, second stage is a viscoelastic behaviour as the resin starts to polymerize, and third stage is a elastic behaviour as the resin is fully cured. The resin is modelled as a 'cure-hardening instantaneously linear elastic material' (CHILE) [1], with an isotropic resin modulus. The fibers are modelled as transverse isotropic material which is independent of the temperature and degree of cure $\left(E_{11 f}, E_{33 f}, G_{13 f}, v_{13 f}, v_{23 f}\right)$. Instantaneous composite material elastic constants are determined using a micromechanics model from Bogetti and Gillespie [8].

The aim of this paper is to propose a 3-D numerical method using finite element to estimate the induced residual stresses and deformations of thermoset polymer unidirectional composites during autoclave curing cycle. These deformations are used to change the autoclave-tool shape design to minimize part deformations. This module will be integrated within an optimization routine in a virtual engineering environment to reduce costs and time of the composite manufacturing process.

\section{Thermo-Chemical Model}

Thermo-chemical module simulation requires the determination of the reaction kinetics of each resin and thermal transport of the heat of reaction across the laminate panel to calculate changes in the laminate temperature that affects thermal strains, and degree of cure that affects resin modulus.

The following mathematical equation is modeled applying transient thermal analysis (ABAQUS).

$$
\begin{gathered}
\rho c_{p} \frac{\partial T}{\partial t}=\frac{\partial}{\partial x_{i}}\left(k_{i j} \frac{\partial T}{\partial x_{j}}\right)+\rho H_{R} \frac{\partial c}{\partial t}+Q_{v} \\
(i, j=1,2,3)
\end{gathered}
$$

where $\rho$ denotes the composite density, $c_{p}$ the specific heat, $T$ the temperature, $t$ the time, $x_{i}$ the coordinates, $k_{i j}$ the components of the thermal conductivity tensor, $c$ the degree of cure, which is defined as the ratio of the heat released by the reaction to the ultimate heat of reaction $H_{R}$, and $\mathrm{Q}_{\mathrm{v}}$ is the heat convection to the surrounding air in the autoclave.

Orthotropic conductivity is assumed for all materials so that values of $k_{11}, k_{22}$, and $k_{33}$ are required. Assuming isotropic resin conductivity and transversely isotropic fibre conductivities, the rule of mixture is used Twardowski [9] to evaluate lamina thermal conductivity, 


$$
\begin{aligned}
& K_{11}=V_{f} \cdot K_{f 11}+\left(1-V_{f}\right) \cdot K_{r} \\
& K_{22}=K_{r} \cdot\left[\left(1-2 \cdot \sqrt{\frac{V_{f}}{\pi}}\right)+\left(\frac{1}{B}\right) \cdot\right. \\
& \left.\left.B-\left(\frac{4}{\sqrt{1-B^{2} \cdot \frac{V_{f}}{\pi}}}\right) \cdot a \tan \left(\frac{\sqrt{1-B^{2} \cdot \frac{V_{f}}{\pi}}}{1+B \cdot \sqrt{\frac{V_{f}}{\pi}}}\right)\right]\right] \\
& B=2 \cdot\left[\left(\frac{K_{r}}{K f_{22}}\right)-1\right]
\end{aligned}
$$

where $\mathrm{K}_{\mathrm{f} 11}, \mathrm{~K}_{\mathrm{f} 22}$ are the longitudinal and transverse conductivities of the fibers, $\mathrm{K}_{\mathrm{r}}$ is the isotropic conductivity of the resin. These values are assumed as a function of temperature. Laminate global conductivity is calculated applying Kulkarni and Brady [12] methodology (Appendix A).

The lamina specific heat capacity is calculated using the following equation [1],

$$
C_{p}=\frac{V_{f} C_{p f} \rho_{f}+\left(1-V_{f}\right) C_{p r} \rho_{r}}{V_{f} \rho_{f}+\left(1-V_{f}\right) C_{p r} \rho_{r}}
$$

where $\mathrm{C}_{\mathrm{pf}}, \mathrm{C}_{\mathrm{pr}}$ are the specific heat of the fibers and resin respectively, and modelled as a function of temperature.

The internal heat generated due to the exothermic cure reaction is described as in White and Hahan [10],

$$
\begin{aligned}
& \frac{d c}{d t}=K \alpha^{m}(1-\alpha)^{n} \\
& K=A e^{-\Delta E / R T}
\end{aligned}
$$

where $\mathrm{K}$ is the Arrhenius rate, $\mathrm{R}=8.31 \mathrm{~J} / \mathrm{Mol} . \mathrm{K}$ is the universe gas constant, $\mathrm{A}$ the frequency factor, and $\Delta \mathrm{E}$ the activation energy.

Heat transfer coefficient for an autoclave of size $(1.8 \mathrm{~m} \times 1.5 \mathrm{~m})$ is measured and can be expressed as [1],

$$
h=20.1+(9.3 E-5) . P \quad\left(W / m^{2} K\right)
$$

\section{Stress-Thermal Model}

The temperature and degree of cure distribution as a function of cure cycle time that is evaluated using the thermo-chemical. Then a sequential transient stress-thermal analysis is used to evaluate residual stresses and deformations. This analysis step involves two 
main issues; Viscoelastic material model to simulate the resin behavior with temperature and degree of cure, and Micromechanical model to predict the composite part Elasticity tensor with time as a function of the fiber and resin material properties.

Modeling the Viscoelastic behavior of a composite material is a complex problem, and is mostly difficult for a curing composite. The most serious difficulties arise from the need to measure material behavior over a wide range of temperatures and degrees of cure and the fact that curing of the resin changes its material response even as it is being tested. The isotropic matrix resin in composite materials is modeled as 'curehardening/instantaneously linear elastic' (CHILE) material. This designation indicates that the modulus of the instantaneously linear elastic resin increases monotonically with the progression of cure. The model for prediction of resin modulus development is that used by Bogetti and Gillespie [8]. The estimation of the CHILE model parameters, requires searching the literature for stress-relaxation test data of the specified epoxy (Hexcel material 914), or performing a set of tests defined by Anderson [1].

$$
\begin{gathered}
E_{r}=\left(1-\alpha_{\mathrm{mod}}\right) \cdot E_{r}^{0}+\alpha_{\mathrm{mod}} \cdot E_{r}^{\infty}+ \\
\gamma \cdot \alpha_{\mathrm{mod}} \cdot\left(1-\alpha_{\mathrm{mod}}\right) \cdot\left(E_{r}^{\infty}-E_{r}^{0}\right) \\
\alpha_{\mathrm{mod}}=\frac{\alpha-\alpha_{C 1}}{\alpha_{C 2}-\alpha_{C 1}}
\end{gathered}
$$

$E_{r}^{0}, E_{r}^{\infty}$ are the fully uncured and fully cured temperature dependent resin modulus. The $\alpha_{C 1}, \alpha_{C 2}$ represent the bounds on degree of cure between which resin modulus is assumed to develop. term $\gamma$ is introduced to account for the competing mechanisms between stress relaxation and chemical hardening [8]. Increasing $\gamma$ physically corresponds to a more rapid increase in modulus at lower degree of cure before asymptotically approaching the fully cured modulus. The fibers are modelled as a transverse isotropic material which is independent on temperature $\left(\mathrm{E}_{11 \mathrm{f}}, \mathrm{E}_{33 \mathrm{f}}, \mathrm{G}_{13 \mathrm{f}}, v_{13 \mathrm{f}}, v_{23 \mathrm{f}}\right)$. The micromechanical model to evaluate the transversely isotropic engineering constants is discussed in Appendix A. User material subroutine (UMAT) is used in ABAQUS to model the material behaviour. Resin chemical shrinkage only occurs during the curing process. Chemical resin shrinkage induces significant macroscopic strains in the composite, representing an important source of internal loading in thick-section laminates in addition to the traditionally recognized thermal expansion strains. The model developed by Bogetti and Gillespie [8] is applied to model the resin chemical shrinkage. The lamina cure shrinkage coefficients are calculated using a micromechanical model (Appendix A) and modeled in user subroutine (UEXPAN). 


$$
\begin{aligned}
& V_{r}^{s}=V_{r}^{s \infty} \cdot \alpha_{s} \\
& \alpha_{s}=\frac{\alpha-\alpha_{C 1}}{\alpha_{C 2}-\alpha_{C 1}}
\end{aligned}
$$

The $\alpha_{\mathrm{C} 1}, \alpha_{\mathrm{C} 2}$ represent the bounds on degree of cure between which resin shrinkage is assumed to develop. $\mathrm{V}_{\mathrm{r}}{ }^{\mathrm{s} \infty}$ is the total volumetric resin shrinkage. Measurements of resin shrinkage during cure is discussed in Anderson [1].

\section{Case Study}

L-shaped angle laminates of AS4/8552 were layed up ply-by-ply on a pair of solid convex aluminium tool as shown in Figure 1 and Figure 2. The autoclave process cycle is shown in Figure 3.

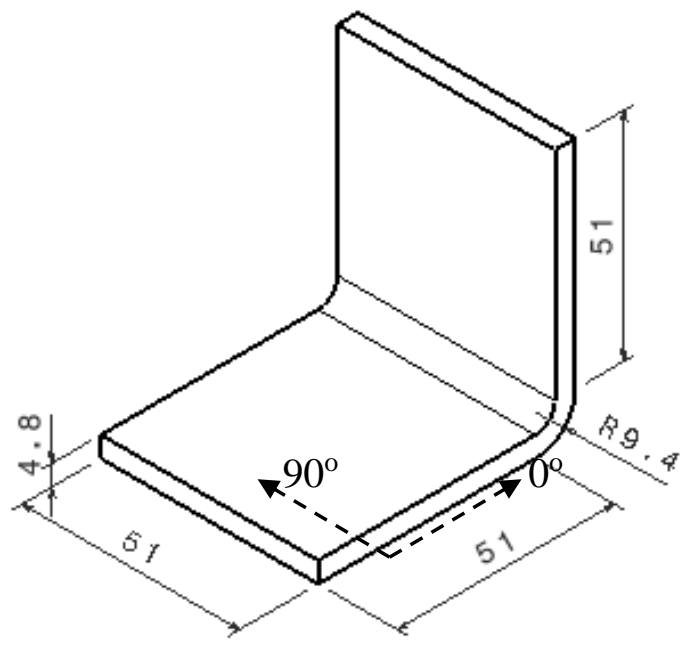

Figure 1. Angle laminate.

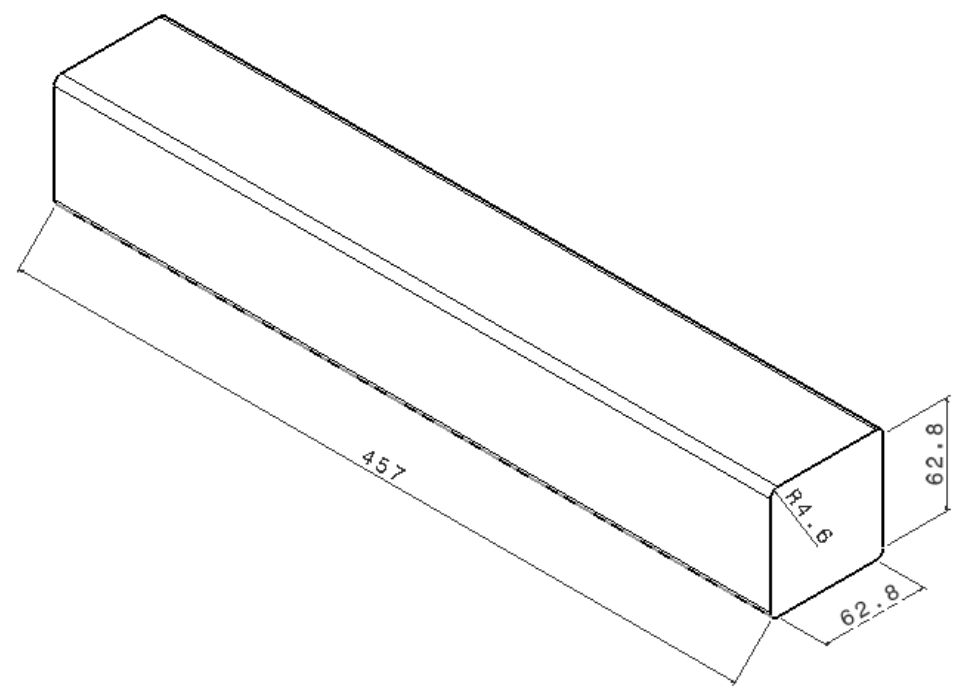

Figure 2. Autoclave tool. 


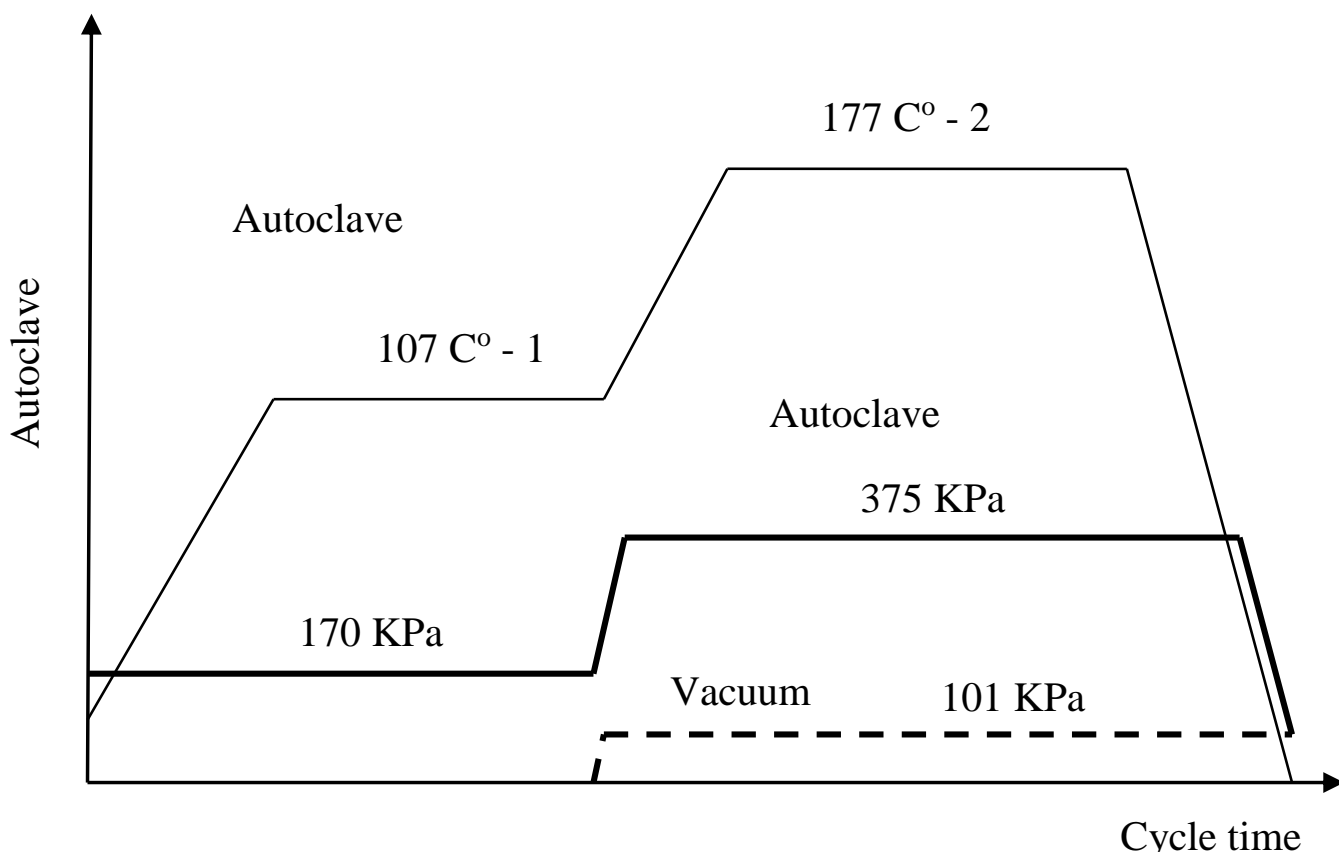

Figure 3. Autoclave process cycle.

composite part is modelled with 3different lay-up; $[90 /+45 /-45 / 0]_{6},[0]_{24}$, and $[90]_{24}$. The angle is meshed with 3-D composite solid elements (C3D8R) [3876 elements], with 6 elements along the depth direction to model bending effect. The autoclave tool is meshed with solid elements (C3D8R) [6955 elements]. Meshed assembly is shown in Figure 4.

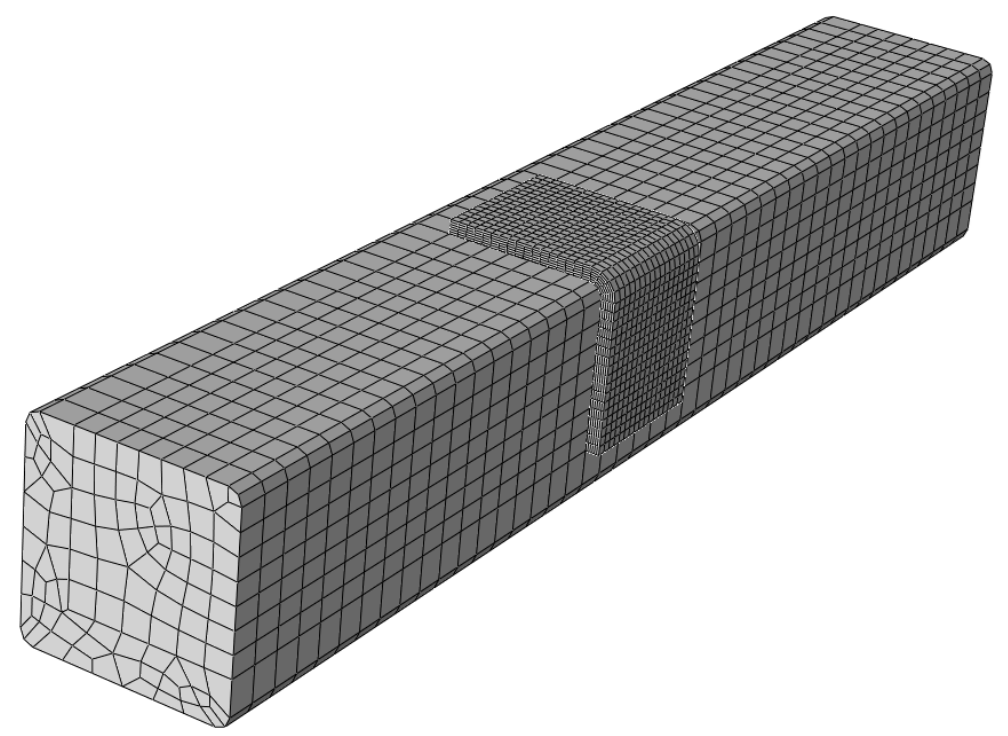

Figure 4. Meshed assembly.

Autoclave process pressure is applied on the outer surface of the angle. Contact surface is defined between the inner surface and the autoclave tool. Mechanical contact properties are defined as rough along the tangential direction and no separation along the normal 
direction of the contact surface. Thermal contact conductance is defined to be $10^{5} \mathrm{~W} / \mathrm{m}^{2}$ $\mathrm{K}$. Autoclave tool is fixed at the bottom left corner and left to slide along the longitudinal and transverse directions of the composite part. Thermal and mechanical material properties used for angle are listed in Table 1 and Table 2 respectively.

Table 1. Thermal material properties.

\begin{tabular}{|c|c|}
\hline $\begin{array}{l}\text { Specific heat } \\
\text { capacity } \\
(\mathrm{J} / \mathrm{Kg} . \mathrm{K})\end{array}$ & $\begin{array}{l}\mathrm{C}_{\mathrm{pf}}=904+(\mathrm{T}-75)(2.05) \\
\mathrm{C}_{\mathrm{pr}}=1005+(\mathrm{T}-20)(3.75)\end{array}$ \\
\hline $\begin{array}{l}\text { Thermal } \\
\text { conductivity } \\
(\mathrm{W} / \mathrm{m} . \mathrm{K})\end{array}$ & $\begin{array}{l}\mathrm{k}_{\mathrm{fl}}=7.69+\mathrm{T}(1.5 \mathrm{E}-2) \\
\mathrm{k}_{\mathrm{ft}}=2.4+\mathrm{T}(5.07 \mathrm{E}-3) \\
\mathrm{k}_{\mathrm{r}}=0.148+\mathrm{T}(3.43 \mathrm{E}-4)\end{array}$ \\
\hline $\begin{array}{l}\text { Fibre volume } \\
\text { fraction }\end{array}$ & $V_{f}=0.573$ \\
\hline $\begin{array}{l}\text { Cure kinetic } \\
\text { model }\end{array}$ & $\begin{array}{l}\mathrm{H}_{\mathrm{R}}=590 \mathrm{E}+3, \Delta \mathrm{E}= \\
66.9 \mathrm{KJ} / \mathrm{gmole}, \mathrm{A} \\
=5.333 \mathrm{E}+5 / \mathrm{s}, \mathrm{m}=0.79 \\
\mathrm{n}=2.16, \alpha_{0}=0.01\end{array}$ \\
\hline
\end{tabular}

Table 2. Mechanical material properties.

\begin{tabular}{|l|l|}
\hline $\begin{array}{l}\text { Resin modulus } \\
\text { development }\end{array}$ & $\begin{array}{l}\mathrm{E}_{\mathrm{r}}^{\infty}=4.67 \mathrm{GPa} \\
\mathrm{E}_{\mathrm{r}}^{0}=\mathrm{E}_{\mathrm{r}}^{\infty} / 10^{2} \\
\alpha_{\mathrm{C} 1}=0.608 ; \alpha_{\mathrm{C} 2}=0.75\end{array}$ \\
\hline $\begin{array}{l}\text { Cure shrinkage } \\
\text { model }\end{array}$ & $\begin{array}{l}\mathrm{V}_{\mathrm{r}}^{\mathrm{s}}=0.099, \alpha_{\mathrm{C} 1}= \\
0.055, \alpha_{\mathrm{C} 2}=0.651\end{array}$ \\
\hline $\begin{array}{l}\text { Fibre volume } \\
\text { fraction }\end{array}$ & $\mathrm{V}_{\mathrm{f}}=0.573$ \\
\hline $\begin{array}{l}\text { Thermal } \\
\text { expansion } \\
\text { coefficient }\end{array}$ & $\mathrm{CTE} 1=0.6 \mathrm{E}-6$, \\
\hline
\end{tabular}




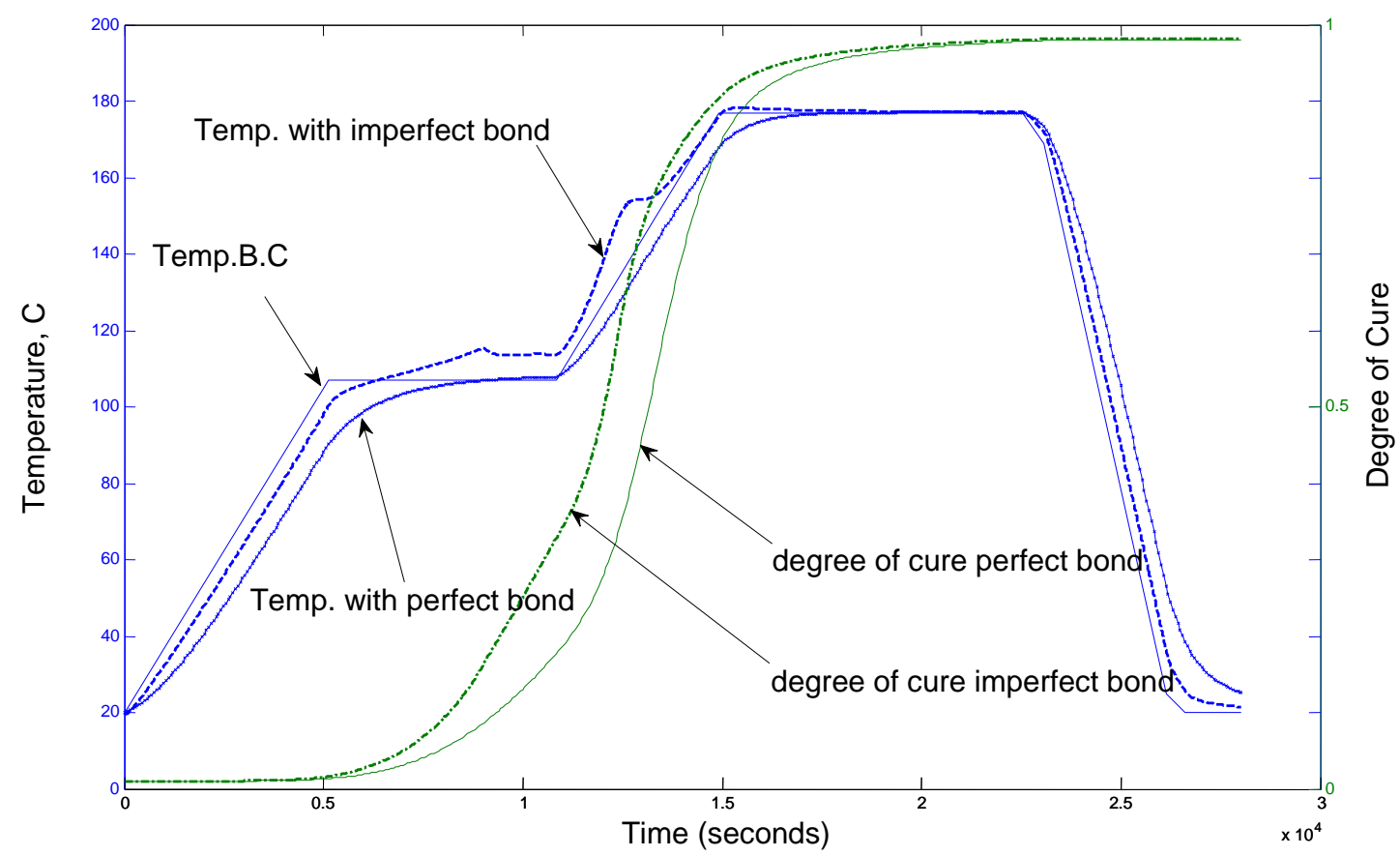

Figure 5. Temperature and degree of cure.

The predicted temperature and degree of cure for two types of thermal bonding between composite part and tool are shown in fig. 5. The exothermic heat could only be simulated only for the low contact conductivity between part and tool. High contact conductivity between part and tool leads to less apparent exothermic heat, which is similar to 2-D results in Anderson [1]. This is due to the high heat transfer rate at the part/tool interface, so the extra heat generated by the resin is rapidly transferred to the tool. Low contact conductivity leads to faster curing rate, due to the higher temperature distribution. Next, these thermal results will be used in the stress-thermal analysis applying the implicit and explicit techniques to calculate part deformations.

The implicit finite element method is an iterative approach and can encounter numerical difficulties when solving non-linear quasi-static problems. The iterative approach employed may have trouble achieving convergence in analyses with a non-linear material behavior and contact analysis. In the case of the explicit FE method the solver equations can be solved directly to determine the solution without iteration, thus providing an alternative, more robust method. Assuming rough tangential contact between part and tool reduces the convergence difficulties, and matches the applied physical boundary condition. On the other side, composite section can be defined in implicit FE and not an option in explicit FE. To overcome this modeling difficulty, an average of the elasticity tensor is calculated and used in the user subroutine (VMAT) to update stress for each integration point.

Following the simulation of the cure cycle, the composite part is removed from tool (remove contact surfaces) in a steady-state analysis step to calculate the final part 
deformations due to residual stresses. Boundary conditions for the tool-removal phase is allowing the plane of symmetry of the part to slide and fix one node on the same plane in all directions. Deformation in the composite part is measured in terms of the contraction of its 90 degrees angle (Fig. 6). Numerical results are shown in Table 3.

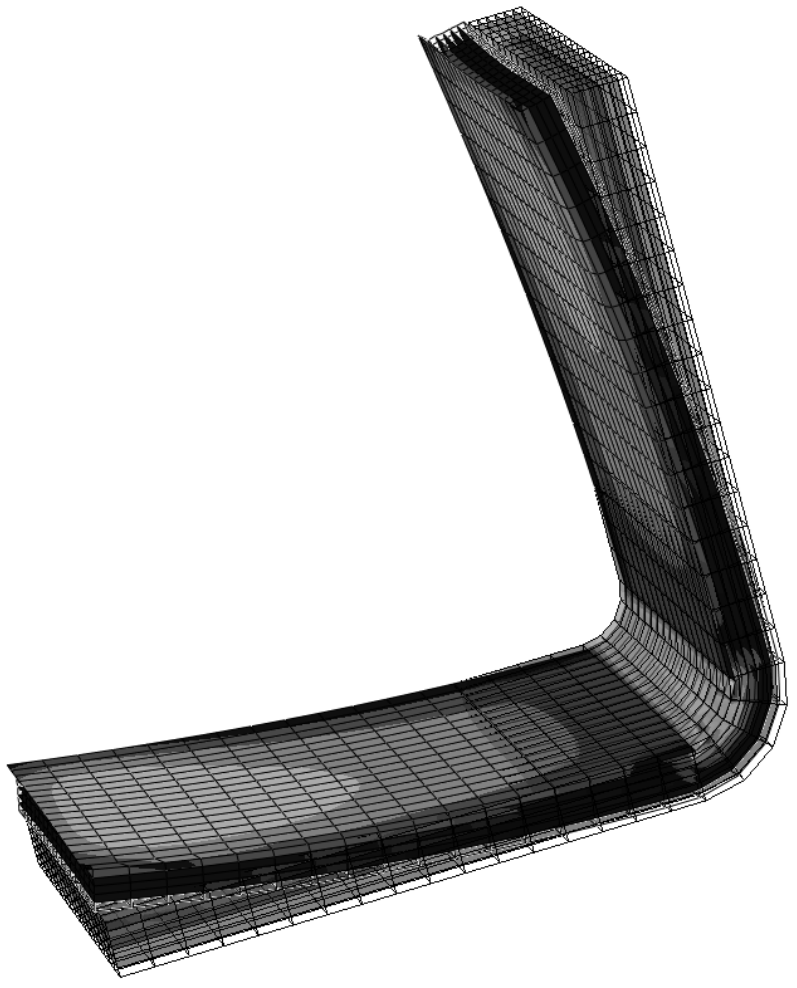

Figure 6. Springback of composite part after being released from tool.

Table 3. Numerical and experimental results.

\begin{tabular}{|l|c|c|c|}
\hline Simulation & $\begin{array}{c}{[90 /-} \\
45 / 45 / 0]_{6}\end{array}$ & {$[0]_{24}$} & {$[90]_{24}$} \\
\hline $\begin{array}{l}\text { 3D Implicit - } \\
\text { high cond. }\end{array}$ & $1.4^{\circ}$ & $1.3^{\circ}$ & $1.3^{\circ}$ \\
\hline $\begin{array}{l}\text { 3D Implicit- } \\
\text { low cond. }\end{array}$ & $1.1^{\circ}$ & $1.2^{\circ}$ & $1.0^{\circ}$ \\
\hline $\begin{array}{l}\text { 3D Explicit- } \\
\text { high cond. }\end{array}$ & $0.9^{\circ}$ & $1.1^{\circ}$ & $0.6^{\circ}$ \\
\hline $\begin{array}{l}\text { 3D Explicit- } \\
\text { low cond. }\end{array}$ & $0.8^{\circ}$ & $1.0^{\circ}$ & $1.1^{\circ}$ \\
\hline Experimental & $1.5^{\circ}$ & $1.7^{\circ}$ & $1.25^{\circ}$ \\
\hline 2D Implicit [1] & $2.3^{\circ}$ & $1.79^{\circ}$ & $0.05^{\circ}$ \\
\hline
\end{tabular}


The higher springback evaluated applying implicit 3-D FE is mostly due to the composite section modeling available in the implicit solver, and on the other hand, averaging methods are used in explicit FE. Another factor is the contact stresses generated by the implicit FE is higher which induces higher deformations. Applying slippery layer between part and tool may reduces contact stresses, which leads to less deformations, but difficult to apply due to the high autoclave temperatures that leads to dryness of the applied layer.

The high conductivity contact between the composite part and tool produced more accurate results, which reflects the true nature of contact in the physical process. And it shows that applying a low conducting layer between the composite part and the tool surface or using low conducting tool can reduce springback. The 2-D implicit FE analysis by Anderson [1] over estimated the springback of the $[90 /+45 /-45 / 0]_{6}$ laminate and did not generate good results for the[90] $]_{24}$ laminate. It can be concluded that $2 \mathrm{D}$ FE analysis is not recommended for cure simulation.

\section{Conclusions}

An approach has been proposed to evaluate the springback deformations during the cure cycle of unidirectional composite materials. The approach was divided into three steps that are integrated together and to be applied in a virtual engineering environment to improve manufacturing and design phases. Numerical results shows the impact of the contact stresses and thermal conductivity on composite part springback. Reducing contact stresses and lowering conductivity between the composite part and tool leads to less deformations. The proposed approach ignored the effect of resin flow which is sometimes used for compacting of laminate and voids removal. Variation of resin distribution may affect springback and it will be the focus of the future work. The same approach will be applied to study springback of 2-D woven composites. A different micromechanical model will be applied to simulate the woven lamina mechanical performance.

\section{Acknowledgments}

The Virtual Engineering Centre is a University of Liverpool project partially funded by NWDA and ERDF. 


\section{Appendix A}

\section{A.1 Global conductivity of laminate composite}

Global lamina conductivity tensor,

$$
\begin{aligned}
& k_{x}=\left|k_{11} \cos \theta\right|+\left|k_{22} \sin \theta\right| \\
& k_{y}=\left|k_{11} \sin \theta\right|+\left|k_{22} \cos \theta\right|, \quad K_{z}=K_{22}
\end{aligned}
$$

where $\theta$ is the fiber orientation angle with respect to the global $\mathrm{x}$-axis.

Global laminate conductivity tensor,

$$
\begin{gathered}
K_{x}=\frac{1}{N} \sum_{i=1}^{N}\left(k_{x}\right)_{i} \\
K_{y}=\frac{1}{N} \sum_{i=1}^{N}\left(k_{y}\right)_{i} \\
K_{z}=\frac{N}{\sum_{i=1}^{N} 1 /\left(k_{z}\right)_{i}}
\end{gathered}
$$

where $i$ denotes each individual lamina, $\mathrm{N}$ is the total number of lamina.

\section{A.2 Engineering constants}

In-Plane moduli,

$$
\begin{aligned}
& E_{11}=E_{1 f} v_{f}+E_{r}\left(1-V_{f}\right)+ \\
& {\left[\frac{4\left(v_{r}-v_{13 f}^{2}\right) k_{f} k_{r} G_{r}\left(1-V_{f}\right) V_{f}}{\left(k_{f}+G_{r}\right) k_{r}+\left(k_{f}-k_{r}\right) G_{r} V_{f}}\right]} \\
& G_{r}=\frac{E_{r}}{2\left(1+v_{r}\right)} ; \quad k=\frac{E}{2\left(1-v-2 v^{2}\right)} \\
& E_{22}=E_{33}=\frac{1}{1 / 4 k_{T}+1 / 4 G_{23}+v_{12}^{2} / E_{11}}
\end{aligned}
$$

Shear moduli,

$$
G_{12}=G_{13}=G_{r}\left[\frac{\left(G_{13 f}+G_{r}\right)+\left(G_{13 f}-G\right) V_{f}}{\left(G_{13 f}+G_{r}\right)-\left(G_{13 f}-G\right) V_{f}}\right]
$$




$$
G_{23}=\frac{G_{r}\left[k_{r}\left(G_{r}+G_{23 f}\right)+2 G_{23 f} G_{r}+k_{r}\left(G_{23 f}-G_{r}\right) V_{f}\right]}{k_{r}\left(G_{r}+G_{23 f}\right)+2 G_{23 f} G_{r}-\left(k_{r}+2 G_{r}\right)\left(G_{23 f}-G_{r}\right) V_{f}}
$$

Poisson's ratios,

$$
\begin{aligned}
& v_{12}=v_{13}=v_{13 f} V_{f}+v_{r}\left(1-V_{f}\right)+ \\
& {\left[\frac{\left(v_{r}-v_{13 f}\right)\left(k_{r}-k_{f}\right) G_{r}\left(1-V_{f}\right) V_{f}}{\left(k_{f}+G_{r}\right) k_{r}+\left(k_{f}-k_{r}\right) G_{r} V_{f}}\right]} \\
& v_{23}=\frac{2 E_{11} k_{T}-E_{11} E_{22}-4 v_{13}^{2} k_{T} E_{22}}{2 E_{11} k_{T}} \\
& k_{T}=\frac{\left(k_{f}+G_{r}\right) k_{r}+\left(k_{f}-k_{r}\right) G_{r} V_{f}}{\left(k_{f}+G_{r}\right)-\left(k_{f}-k_{r}\right) V_{f}}
\end{aligned}
$$

Cure shrinkage coefficients,

$$
\begin{aligned}
& C S C_{1}=\frac{E_{r}\left(1-V_{f}\right)}{E_{11 f} V_{f}+E_{r}\left(1-V_{f}\right)} \\
& C S C_{2}=\left(1+v_{r}\right)\left(1-V_{f}\right)-\left[v_{13 f} V_{f}+v_{r}\left(1-V_{f}\right)\right] . \\
& {\left[\frac{E_{r}\left(1-V_{f}\right)}{E_{11 f} V_{f}+E_{r}\left(1-V_{f}\right)}\right]} \\
& \operatorname{CSC}_{3}=C S C_{2}
\end{aligned}
$$

Cure shrinkage strains,

$$
\varepsilon_{i}^{s}=C S C_{i} \cdot\left(\varepsilon_{i}^{s(k)}-\varepsilon_{i}^{s(k-1)}\right)
$$

$\mathcal{E}_{\mathrm{r}}^{\mathrm{s}(\mathrm{k})} \mathcal{E}_{\mathrm{r}}^{\mathrm{s}(\mathrm{k}-1)}$ are the total cure shrinkage strains at the start and end of the time step respectively.

$$
\varepsilon_{r}^{s}=\left(1+V_{r}^{s}\right)^{1 / 3}-1
$$

\section{A.3 Elasticity tensor calculations (VMAT)}

3-D stress/strain transformation matrix, for the calculations of the average elasticity tensor in VMAT subroutine, 


$$
T=\left[\begin{array}{cccccc}
\cos \theta^{2} & \sin \theta^{2} & 0 & 2 * \sin \theta^{*} \cos \theta & 0 & 0 \\
\sin \theta^{2} & \cos \theta^{2} & 0 & -2 * \sin \theta^{*} \cos \theta & 0 & 0 \\
0 & 0 & 1 & 0 & 0 & 0 \\
-\sin \theta^{*} \cos \theta & \sin \theta^{*} \cos \theta & 0 & \cos \theta^{2}-\sin \theta^{2} & 0 & 0 \\
0 & 0 & 0 & 0 & \cos \theta & -\sin \theta \\
0 & 0 & 0 & 0 & \sin \theta & \cos \theta
\end{array}\right]
$$

Transformed elasticity tensor for lamina,

$$
[C]_{i}^{G}=T_{\theta}^{-1}[C]\left(T_{\theta}^{-1}\right)^{T}
$$

Average elasticity tensor,

$$
\begin{gathered}
{[C]^{A}=\frac{\sum_{N}[C]_{i}^{G}}{N}} \\
{[C]^{-1}=\left[\begin{array}{cccccc}
1 / E_{11} & -v_{12} / E_{11} & -v_{13} / E_{11} & 0 & 0 & 0 \\
-v_{12} / E_{11} & 1 / E_{22} & -v_{23} / E_{22} & 0 & 0 & 0 \\
-v_{13} / E_{11} & -v_{23} / E_{22} & 1 / E_{33} & 0 & 0 & 0 \\
0 & 0 & 0 & 1 /\left(2 . G_{12}\right) & 0 & 0 \\
0 & 0 & 0 & 0 & 1 /\left(2 . G_{23}\right) & 0 \\
0 & 0 & 0 & 0 & 0 & 1 /\left(2 . G_{31}\right)
\end{array}\right]}
\end{gathered}
$$

\section{References}

[1] Johnston, A. A. (1997), An Integrated Model of the Development of Process-Induced Deformation in Autoclave Processing of Composite Structures. PhD dissertation, University of British Columbia.

[2] W.I. Lee, A.C. Loos, and G.S. Springer (1997), Heat of Reaction, Degree of Cure, and Viscosity of Hercules 3501-6 Resin, Journal of Composite Materials 16, 510 520.

[3] S.N. Lee, M.T. Chiu, and H.S. Lin (1992), Kinetic Model for the Curing Reaction of a Tetraglycidyl Diamino-Diphenyl Methane/Diamino Diphenyl Sulfone (TGDDM/DDS) Epoxy Resin System, Polymer Engineering and Science 32 (15), 1037-1046.

[4] E.P. Scott (1991), Determination of Kinetic Parameters Associated with the Curing of Thermoset Resins Using Dielectric and DSC Data, Composites: Design, Manufacture, and Application, ICCM/VIII, Honolulu, 10-0- 1-10.

[5] A. Johnston and P. Hubert (1994), Effect of Processing Variables on Springback of Composite Angles. A Report to the Boeing Company. 
[6] Capehart T. W., Kia H. G. and Abujoudeh T. (2007), Cure Simulation of Thermoset Composite Panels, J. of Composite Materials, 41, 1339-1360.

[7] A.M. Boriek, J.E. Akin, and C.D. Armeniades (1988), Setting Stress Distribution in Particle Reinforced Polymer Composites", J. of Composite Materials 22, 986-1002.

[8] T.A. Bogetti and J.W. Gillespie Jr. (1992), "Process-Induced Stress and Deformation in Thick-Section Thermoset Composite Laminates", Journal of Composite Materials 26 (5), 626-660.

[9] M. R. Kulkarni and R. P. Brady (1996), A Model of Global Thermal Conductivity in Laminated Carbon/Carbon Composites, J. of composite Science and Technology 57, 277-285.

[10] S.R. White and H.T. Hahn (1992), "Process Modeling of Composite Materials: Residual Stress Development during Cure. Part I. Model Formulation", J. of Composite Materials 26 (16), 2402-2422. 